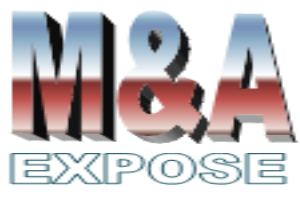

http://jurnal.usahid.ac.id/index .php/accounting
${ }^{1}$ Fakultas Teknik Universitas Sahid lailahardian@gmail.com psdyah@gmail.com marioegga19@gmail.com

\section{Penentuan Nilai Biaya Perjalanan Pada Pusat Konservasi Tumbuhan Kebun Raya Bogor}

\author{
Laila Febrina ${ }^{1}$, Purnomo Sutji Dyah Prinadjati ${ }^{1}$, \\ Muhammad Egga Arigayo'
}

\section{Abstrak}

Kebun Raya Bogor (KRB) adalah kawasan konservasi di Bogor yang menjadi wahana berbagai tanaman tropis terbesar di dunia. Secara ekologis, keberadaan KRB sebagai penyerap karbon dioksida, penghasil oksigen, area penyerapan air, nilai estetika. Secara ekonomi, KRB telah berkontribusi pada upaya meningkatkan pendapatan negara dari atraksi dan meningkatkan pendapatan daerah di kota Bogor. Tujuan penelitian ini adalah untuk menganalisis persepsi pengunjung KRB, menganalisis faktorfaktor yang mempengaruhi fungsi permintaan rekreasi, serta menilai permintaan ekonomi untuk pariwisata di KRB. Kuesioner persepsi pengunjung dianalisis deskriptif menggunakan skala Likert, metode perumusan fungsi permintaan dan pendekatan biaya perjalanan digunakan untuk memperkirakan permintaan untuk pariwisata KRB dan nilai ekonominya. Permintaan pariwisata KRB dimodelkan dalam bentuk regresi linier berganda. Permintaan wisata atau frekuensi kunjungan seseorang ke KRB dipengaruhi secara signifikan oleh biaya perjalanan dan usia pengunjung.

Kata kunci : Persepsi Pengunjung, Nilai Ekonomi, Metode Biaya Perjalanan.

\section{Abstract}

Bogor Botanical Gardens (KRB) is a conservation area in Bogor which is a basket for a variety of the largest tropical plants in the world. Ecologically, the existence of KRB as carbon dioxide absorber, oxygen producer, water absorption area, aesthetic value. Economically, KRB has contributed to efforts to increase state revenue from attractions and increase regional income in the city of Bogor. The purpose of this study is to analyze the perceptions of $K R B$ visitors, analyze the factors that influence the function of recreational demand, and assess economic demand for tourism in $K R B$. The visitor perception questionnaire was analyzed descriptively using a Likert scale, the method of formulating the demand function and the travel cost approach were used to estimate demand for KRB tourism and its economic value. KRB tourism demand is modeled in the form of multiple linear regression. Travel demand or the frequency of one's visit to KRB is significantly influenced by travel costs and visitor age.

Keywords: Visitor Perception, Economic Value, Travel Cost Method. 


\section{PENDAHULUAN}

Pariwisata merupakan salah satu industri terbesar dalam sektor jasa dengan tingkat pertumbuhan paling pesat di dunia saat ini. Bersama dengan industri teknologi dan informasi, industri pariwisata diperkirakan menjadi penggerak utama perekonomian abad 21 (Efendi, 2015). Kota Bogor merupakan kota yang memiliki banyak potensi wisata. Jenis wisata yang berada di Kota Bogor meliputi wisata alam, wisata seni dan kebudayaan, wisata kuliner dan wisata sejarah (Masmaulidia, 2017). Salah satu objek wisata alam terbesar di Kota Bogor adalah Kebun Raya Bogor (KRB). Kebun Raya Bogor adalah sebuah kebun penelitian besar yang terletak di Kota Bogor, berjarak 60 kilometer dari Jakarta. Luas KRB mencapai 87 hektar dan memiliki 15.000 jenis koleksi pohon dan tumbuhan. KRB terletak pada ketinggian 235-260 meter di atas permukaan laut (mdpl), serta mempunyai ketinggian rata-rata minimal 190 meter, maksimal 350 meter.

Pengunjung merupakan fokus utama dari kegiatan kunjungan di Pusat Konservasi Tumbuhan Kebun Raya Bogor. Berdasarkan data dari Pusat Konservasi Tumbuhan Kebun Raya Bogor, jumlah pengunjung pada periode 2012-2017 sebagaimana Gambar 1.

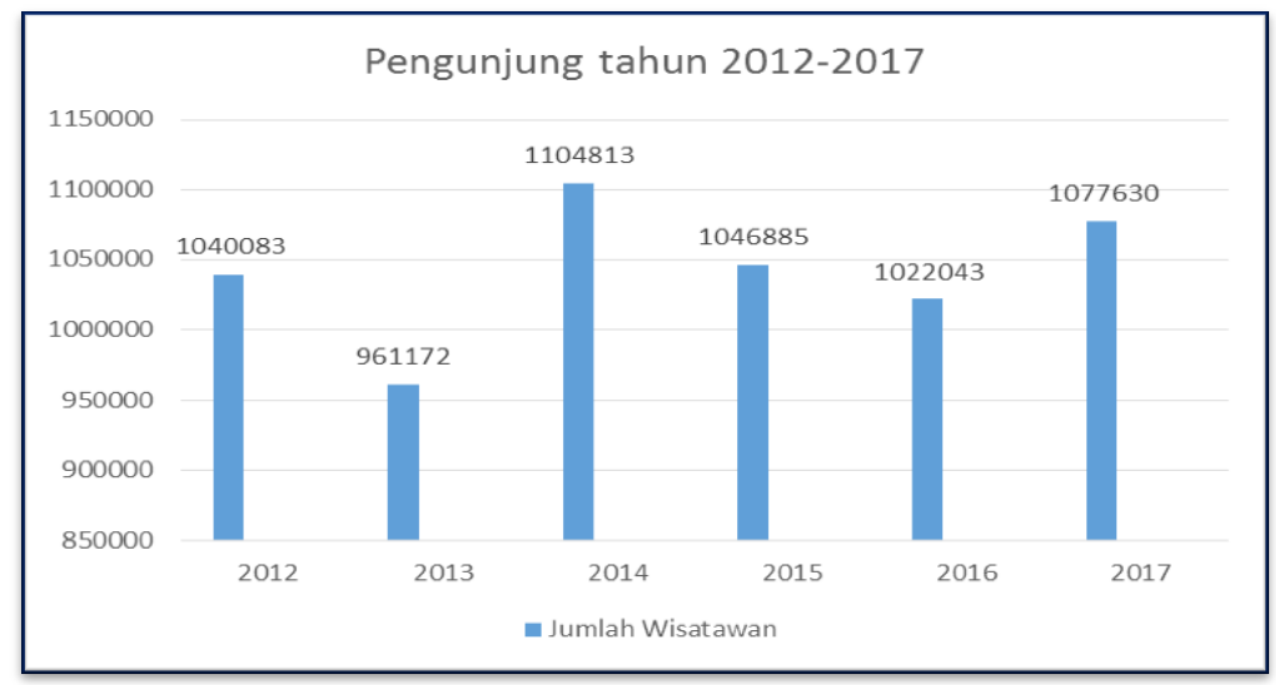

Gambar 1. Grafik Kunjungan Wisatawan ke KRB dalam kurun 2012-2017

KRB merupakan salah satu pusat konservasi tumbuhan yang mengoleksi tumbuhan tropis terbesar di dunia dan merupakan salah satu contoh hutan kota yang terletak di tengah-tengah kota. Keberadaan pusat konservasi Kebun Raya Bogor sebagai hutan kota ini sangat bermanfaat karena berfungsi sebagai penjaga dan memperbaiki iklim, pusat konservasi, objek wisata dan juga sebagai sarana pembelajaran bagi wisatawan dan pelajar yang berkunjung.

Kota Bogor dengan wisata Kebun Raya Bogor menjadi daya tarik tersendiri untuk pariwisata. Kekayaan alam Indonesia yang beraneka ragam dengan biodiversitasnya termasuk keanekaragaman tumbuhan menjadi salah satu sebab wisatawan datang berkunjung ke Kebun raya Bogor. Berbagai macam tanaman dapat tumbuh subur di sini. Bahkan tidak sedikit dari tanaman tersebut yang bersifat langka atau sangat sulit sekali untuk ditemukan sehingga harus dilindung. 
Keberadaan KRB saat ini sangat berpengaruh dari segi ekonomi dan mempunyai andil penting dalam usaha meningkatkan pendapatan negara, yaitu dari kunjungan wisatawan setiap tahunnya serta menambah pendapatan pemerintah daerah Kota Bogor melalui kontribusinya dari penerimaan tiket masuk. Objek wisata ini memberikan manfaat yang tidak nyata, di mana manfaat ekonomi tidak dapat di kuantifikasikan secara langsung karena tidak ada pasar untuk barang tersebut sebagai penilaian ekonomi terhadap barang publik sering dinyatakan sebagai barang bebas yang membutuhkan suatu pendekatan penilaian tertentu. Pendekatan yang dapat dilakukan untuk mengetahui nilai ekonomi jasa wisata adalah dengan teknik pengukuran tidak langsung berupa travel cost method (TCM) atau metode biaya perjalanan. Penentuan nilai jasa wisata dengan metode ini sangat bergantung pada penilai (pengunjung) sehingga perlu diketahui karakteristik pengunjung objek wisata tersebut. Hasil dari nilai ekonomi jasa wisata dapat menjadi salah satu bahan pertimbangan dalam pengembangan bentuk-bentuk layanan oleh manajemen pengelola objek wisata (Fauzi, 2013).

Berdasarkan latar belakang tersebut, maka yang menjadi tujuan dalam penelitian ini adalah :

1. Mengetahui penilaian pengunjung wisata terhadap pusat konservasi tumbuhan Kebun Raya Bogor.

2. Menganalisis faktor-faktor yang mempengaruhi intensitas kunjungan wisatawan ke pusat konservasi tumbuhan Kebun Raya Bogor.

3. Menganalisis nilai ekonomi manfaat berdasarkan metode analisis Travel Cost Metode.

\section{TINJAUAN PUSTAKA}

Pada prinsipnya valuasi ekonomi bertujuan untuk memberikan nilai ekonomi kepada nilai ekonomi wisata, sumber daya alam dan lingkungan yang digunakan sesuai dengan nilai riil dari sudut pandang masyarakat. Valuasi ekonomi digolongkan menjadi dua kelompok. Teknik penilaian pertama mengandalkan harga implisit di mana Willingness To Pay (keinginan membayar) terungkap melalui model yang dikembangkan, meliputi Travel Cost, Hedonic Pricing, dan Random Utility Model. Teknik penilaian kedua adalah penilaian yang didasarkan pada survei, di mana Willingness To Pay (keinginan membayar) diperoleh dari respon yang diperoleh dari responden, meliputi Contingent Valuation, Random Utility Model dan Contingent Choice.

Teknik yang akan digunakan dalam penelitian ini dan sudah berhasil untuk menilai ekonomi suatu kawasan wisata adalah dengan metode biaya perjalanan (Travel Cost Metode). Dalam metode tersebut, dianalisis biaya yang dikeluarkan pengunjung selama melakukan wisata guna menaksir nilai ekonomi wisata, sumber daya alam dan lingkungan. Frekuensi kunjungan dan faktor-faktor yang mempengaruhi kunjungan wisatawan juga dianalisis agar menjadi masukan bagi pengelolaan Kebun Raya Bogor. Berdasarkan metode Travel Cost Metode ini juga dapat diketahui kesediaan pengunjung untuk membayar tiket apabila mengalami kenaikan harga. Penentuan nilai jasa wisata dengan metode tersebut lebih riil dan up to date dalam mengilustrasikan karakteristik pengunjung objek wisata KRB. Selanjutnya analisis nilai ekonomi jasa wisata dapat menjadi salah satu bahan pertimbangan bagi pihak manajemen KRB dalam meningkatkan layanannya bagi pengunjung objek wisata (Fauzi, 2013). 


\section{METODE PENELITIAN}

Penelitian dilaksanakan di Kebun Raya Bogor yang terletak di Kota Bogor, yang terdiri dari area koleksi tanaman, jalur sirkulasi, lapangan parkir, museum, kebun pembibitan, rumah kaca, perkantoran, dan rumah pegawai. Areal koleksi tanaman yang dapat dikunjungi oleh pengunjung memiliki luas sekitar 53 hektar.

Desain penelitian ini merupakan penelitian deskriptif untuk mengetahui nilai ekonomi dari pusat konservasi tumbuhan Kebun Raya Bogor, intensitas pengunjung serta faktorfaktor yang mempengaruhi intensitas pengunjung.

Populasi penelitian ini adalah pengunjung obyek wisata Kebun Raya Bogor. Media yang digunakan berupa kuisioner, alat tulis, papan jalan, dan kamera. Jenis data yang digunakan dalam penelitian ini adalah data primer dan data sekunder. Data primer adalah data yang diambil secara langsung di lapangan, berupa data biaya perjalanan dan karakteristik pengunjung. Data sekunder merupakan data pustaka yang didapat dari pengelola maupun pihak lain berupa data kondisi umum dan jumlah pengunjung di Kebun Raya Bogor.

Teknik yang digunakan dalam memilih sampel adalah teknik accidental sampling. Teknik pengambilan sampel ini dengan cara memilih siapa saja yang kebetulan dijumpai pada saat inspeksi. Dalam penentuan jumlah sampel digunakan rumus Slovin (Arikunto, 2003), sebagai berikut :

$$
n=\frac{N}{1+N e^{2}}
$$

Keterangan :

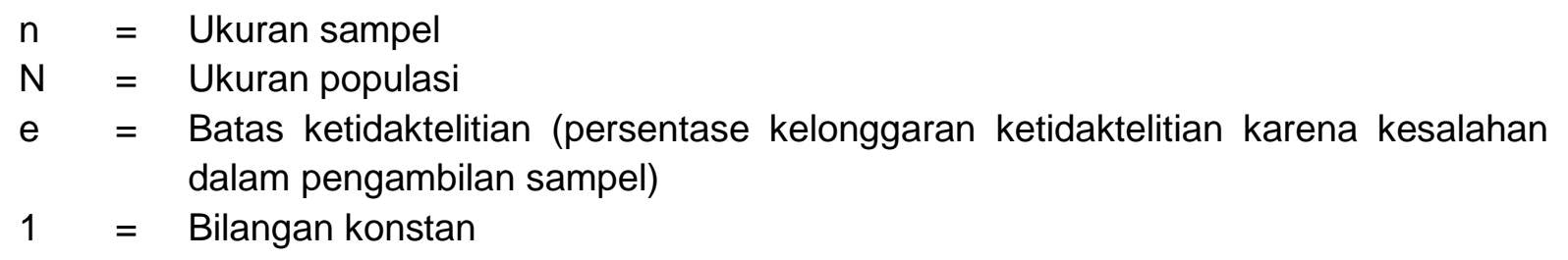

Jumlah rata - rata pengunjung Kebun Raya Bogor selama periode 2012-2016 adalah 1.034.999 orang. Jumlah tersebut menunjukkan angka lebih besar dari 100 sehingga dalam penelitian ini digunakan batas error 10 persen (Arikunto, 2003). Hal ini dilakukan guna mengurangi penyimpangan dengan batas error $\leq 0,1$ alpha.

$$
\begin{aligned}
& n=\frac{N}{1+N e^{2}} \\
& n=\frac{1.034 .999}{1+1.034 .999(0.1)^{2}} \\
& n=\frac{1.034 .999}{1+10.349,99} \\
& n=\frac{1.034 .999}{10.350,99} \\
& n=99,9
\end{aligned}
$$


Berdasarkan perhitungan tersebut maka jumlah sampel yang dibutuhkan, yaitu 100 orang. Demi mengadopsi keragaman pengunjung, maka pengumpulan data dilakukan pada hari biasa dan akhir pekan.

Variabel dalam penelitian ini meliputi :

1. Biaya Perjalanan

Biaya perjalanan merupakan biaya yang dikeluarkan seseorang selama melakukan rekreasi pada suatu tempat wisata tertentu yang terdiri dari biaya transportasi, biaya konsumsi, biaya parkir dan biaya bahan bakar, biaya dokumentasi dan biaya lainnya, kecuali tiket masuk.

2. Tingkat Usia

Tingkat usia diduga sangat mempengaruhi keputusan seseorang untuk melakukan rekreasi. Hal ini dikarenakan usia dapat menggambarkan kemampuan fisik seseorang, kemampuan hidup, dan lain-lain (Supriyatna, 2004).

3. Pendapatan

Tingkat pendapatan berhubungan erat dengan kemampuan seseorang untuk memutuskan tujuan rekreasi. Semakin tinggi pendapatan seseorang maka keinginan untuk melakukan rekreasi semakin tinggi (Suharti, 2007).

4. Pendidikan

Tingkat pendidikan sangat mempengaruhi keinginan seseorang dalam melakukan kegiatan wisata. Seseorang yang memiliki pendidikan tinggi, biasanya tingkat kepenatan dan kejenuhan yang dimilikinya akibat rutinitas sehari-hari semakin tinggi (Supriyatna, 2004).

5. Waktu Tempuh

Waktu tempuh dihitung berdasarkan waktu yang digunakan seseorang untuk menempuh perjalanan dari lokasi asal hingga ke lokasi wisata dan kembali lagi ke tempat tujuan.

Metode analisis data adalah analisa kuantitatif, sebagai berikut :

1. Untuk menganalisis persepsi pengunjung menggunakan analisis deskriptif.

2. Untuk menganalisis faktor yang mempengaruhi intensitas pengujung menggunakan fungsi permintaan.

3. Untuk mengetahui nilai ekonomi manfaat dari Kebun Raya Bogor digunakan analisis Travel Cost Method.

\section{HASIL DAN PEMBAHASAN}

Persepsi Pengunjung. Persepsi pengunjung KRB dipetakan sebagaimana kriteria interpretasi skor berikut :

Tabel 1. Kriteria Persepsi Pengunjung

\begin{tabular}{ccc}
\hline No. & Skala & Kriteria \\
\hline 1. & Angka $0 \%-19,99 \%$ & Sangat kurang sekali \\
2. & Angka $20 \%-39,99 \%$ & Kurang baik \\
3. & Angka $40 \%-59,99 \%$ & Cukup \\
4. & Angka $60 \%-79,99 \%$ & Baik \\
5. & Angka $80 \%-100 \%$ & Sangat baik \\
\hline
\end{tabular}


Berdasarkan analisis deskriptif atas kuesioner yang disebarkan kepada responden maka didapatkan hasil penilaian pengunjung terhadap KRB sebesar 73,94 persen. Merujuk pada kriteria interpretasi skor yaitu pada kategori antara angka 60 persen hingga 79,99 persen sehingga termasuk kategori Baik. berikut.

Hasil persepsi pengunjung di Kebun Raya Bogor dapat dilihat pada gambar 2

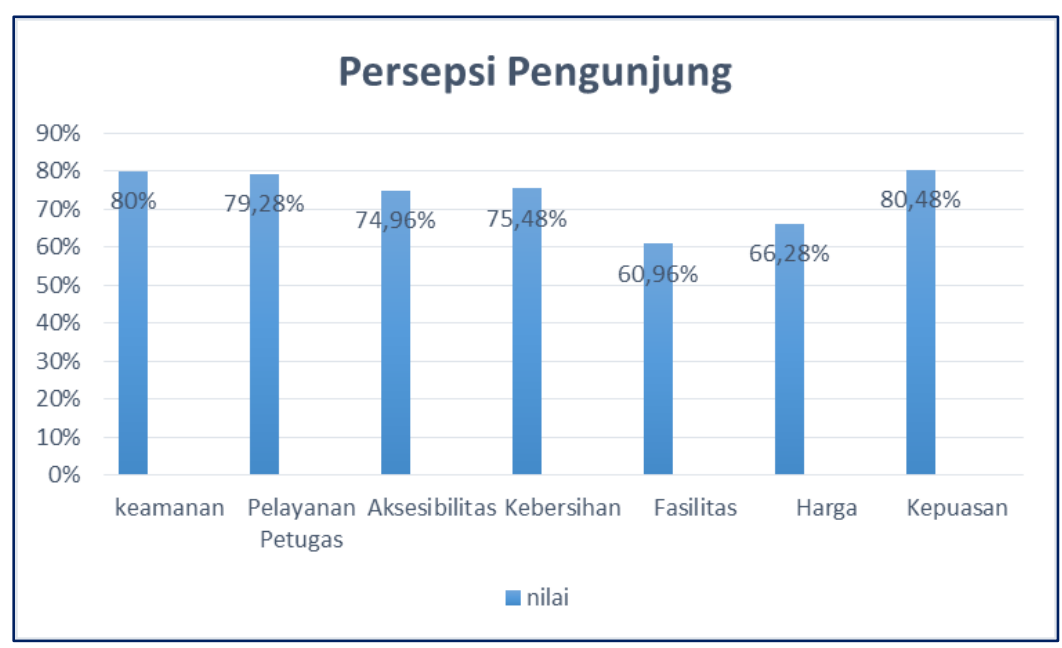

Gambar 2. Persepsi Wisatawan di Kebun Raya Bogor

Fungsi Permintaan. Untuk menganalisis jumlah intensitas kunjungan wisatawan ke Kebun Raya Bogor maka digunakan lima variabel untuk merumuskan model persamaan fungsi permintaan rekreasi berikut :

$$
Y=2,502+2,249 E-6 X_{1}-0.07 X_{2}+0,187 X_{3}-0,093 X_{4}+0,012 X_{5}
$$

\section{Keterangan :}

$Y \quad$ Jumlah intensitas kunjungan ke lokasi KRB

$\mathrm{X} 1 \quad$ Biaya Perjalanan (Rp)

X2 Waktu tempuh dari tempat tinggal ke KRB (jam)

X3 Umur responden (tahun)

X4 Tingkat pendidikan responden (pendidikan terakhir).

X5 pendapatan yang menjadi penghasilan responden (Rp/bulan)

b0 Konstanta

b1-b5 Koefisien regresi.

e Error

Dari hasil uji regresi linear berganda dari persamaan di atas, koefisien yang signifikan adalah biaya perjalanan (X1) dan usia (X3), maka persamaan fungsi permintaan yang akurat menjadi :

$$
Y=2,502+2,249 E-6 X_{1}+0,187 X_{3}
$$


Berdasarkan analisis regresi, didapatkan nilai $R^{2}$ sebesar 7,3 persen dan $R^{2}(a d j)$ sebesar 2,4 persen. Hal ini dapat diartikan bahwa keragaman permintaan jumlah kunjungan ke Kebun Raya Bogor dapat dijelaskan oleh variabel-variabel bebas dalam model sebesar 7,3 persen, sedangkan sisanya sebesar 92,7 persen dijelaskan oleh variabel-variabel lain di luar model. Selain itu, dari hasil analisis regresi dinyatakan bahwa tidak terdapat pelanggaran asumsi OLS (Ordinary Least Square) seperti multikolinearitas, heteroskedastisitas dan autokorelasi pada model.

Dengan demikian faktor-faktor yang signifikan mempengaruhi fungsi permintaan kunjungan ke Kebun Raya Bogor adalah :

a. Biaya Perjalanan

Biaya perjalanan dapat diartikan sebagai biaya yang seluruhnya dikeluarkan oleh setiap pengunjung dalam satu kali melakukan kegiatan rekreasi. Biaya perjalanan meliputi biaya transportasi, dokumentasi, konsumsi selama rekreasi, parkir, pembelian souvenir dan biaya lainnya, kecuali biaya tiket masuk lokasi rekreasi. Variabel biaya perjalanan berpengaruh secara signifikan pada $\alpha=20$ persen sehingga dapat dikatakan bahwa variabel tersebut 80 persen berpengaruh nyata terhadap frekuensi kunjungan. Hal tersebut dapat disebabkan karena variabel biaya tersebut tidak dapat dipisahkan dengan frekuensi kunjungan seseorang. Koefisien variabel ini memiliki tanda positif, hal itu sesuai dengan teori ekonomi yang menyatakan semakin tinggi biaya perjalanan seseorang maka akan semakin tinggi pula konsumsinya. Jadi, apabila seseorang biaya perjalanannya tinggi maka mereka cenderung akan meningkatkan rata-rata frekuensi kunjungannya ke tempat rekreasi.

b. Usia

Variabel usia berpengaruh secara signifikan pada $\alpha=10$ persen sehingga dapat dikatakan bahwa variabel tersebut 90 persen berpengaruh nyata terhadap frekuensi kunjungan. Oleh karena itu dalam penelitian ini usia mempunyai pengaruh yang searah dengan frekuensi kunjungan. Hal ini berarti semakin dewasa umur seseorang maka akan meningkatkan peluang rata-rata frekuensi kunjungan. Hal ini dapat disebabkan karena orang yang lebih dewasa dengan beragam aktifitas membutuhkan waktu untuk berekreasi mengingat tujuan dari rekreasinya.

Surplus Konsumen Dan Nilai Ekonomi. Pendekatan biaya perjalanan merupakan dasar untuk menduga besarnya surplus konsumen. Surplus konsumen merupakan proxy dari nilai Wilingness to Pay (WTP)/keinginan membayar terhadap lokasi rekreasi yang dikunjungi. Menurut Fauzi (2004), surplus konsumen bisa didapatkan dengan cara rumus dari Surplus Konsumen sebagai berikut :

$$
S K=\left(\frac{n^{2}}{2 . b 1}\right): \text { per kunjungan individu }
$$

Keterangan :

$\mathrm{n}^{2}=$ jumlah kunjungan kuadrat

$b_{1}=$ koefisien biaya perjalanan

Mengacu pada konsep WTP yang dibangun, maka nilai WTP pengunjung adalah sebesar nilai surplus konsumen. Dengan menggunakan rumus tersebut, dan berdasarkan hasil analisis regresi linier berganda didapatkan surplus konsumen atau nilai WTP 
pengunjung dengan pendekatan biaya perjalanan sebesar Rp. 60.515 per individu per kunjungan.

Nilai ekonomi merupakan agregat atau penjumlahan WTP. Dengan demikian, nilai ekonomi dari KRB berdasarkan metode biaya perjalanan individual diperoleh dengan mengalikan WTP dengan jumlah pengunjung selama tahun 2012-2016. Berikut adalah rumus nilai ekonomi adalah :

\section{Nilai Ekonomi KRB = (jumlah SK individu kunjungan)xjumlah kunjungan}

Jumlah total pengunjung selama periode 2012-2016 sebesar 5.174.996 pengunjung, sehingga dari hasil tersebut dieroleh nilai ekonomi KRB sebesar Rp 313.164.882.940.

Penentuan strategi pengelolaan KRB yang optimal ialah dengan membandingkan penerimaan KRB, dalam hal ini nilai ekonomi wisata KRB yang diperoleh dari surplus konsumen sebagai proxy dari nilai WTP terhadap lokasi rekreasi dengan biaya pengelolaan KRB. Strategi pengelolaan KRB dikatakan optimal jika nilai ekonomi wisata lebih besar daripada biaya pengelolaan sebaliknya, jika nilai ekonomi wisata lebih kecil daripada biaya pengelolaan, maka strategi pengelolaan KRB belum optimal (Rizki, 2007). Untuk meminimalkan kerugian KRB akibat belum optimalnya pengelolaan, pengelola dapat mengupayakan dengan menaikkan tarif masuk KRB atau dengan menambah fasillitas dan wahana bermain anak yang dapat menarik minat pengunjung dengan tetap menjaga keanekaragaman tumbuhan yang ada di KRB.

Hasil pengeluaran KRB menunjukkan bahwa, pengeluaran KRB pada tahun 20122016 sebesar $\mathrm{Rp}$ 60.344.500.710 sedangkan nilai ekonomi wisata yang diperoleh KRB pada periode tahun 2012 sampai 2016 sebesar Rp 313.164.882.940. Biaya pengelolaan KRB lebih kecil dari nilai ekonomi wisata $\mathrm{KRB}$, dengan hasil perhitungan sebesar Rp. 252.820.382.230 Hal ini menunjukkan keuntungan yang dialami KRB sehingga dapat ditarik kesimpulan bahwa pengelolaan KRB sudah mencapai optimal.

\section{KESIMPULAN}

Terdapat dua faktor sosial ekonomi yang berpengaruh terhadap fungsi permintaan rekreasi Kebun Raya Bogor, yaitu biaya perjalanan dan umur. Hasil analisis keseluruhan penilaian dari beberapa item penilaian pengunjung terhadap Kebun Raya Bogor yang merujuk pada kriteria interpretasi skor termasuk pada kategori Baik.

Analisis Travel Cost Method menunjukkan bahwa surplus konsumen berdasarkan metode biaya perjalanan individual sebesar Rp. 60.515 per individu per kunjungan, sedangkan nilai ekonomi Kebun Raya Bogor sebesar Rp. 313.164.882.940. Hal ini menunjukkan bahwa pengelolaan Kebun Raya Bogor mengalami keuntungan sebesar Rp. 252.820.382.230 dan pengelolaan tersebut sudah mencapai optimal.

\section{DAFTAR PUSTAKA}

Efendi, A. 2015. Nilai Ekonomi Jasa Wisata Pulau Tangkil Provinsi Lampung Dengan Pendekatan Metode Biaya Perjalanan. Jurnal Sylva Lestari, Vol 3, No.3. 
Fauzi, R. 2013. Valuasi ekonomi Taman Nasional Kelimutu melalui Pendekatan Nilai Ekonomi Wisata. Tesis. Program Pascasarjana IImu Ekonomi, Universitas Indonesia. Jakarta.

Fauzi, A. 2006. Ekonomi Sumber Daya Alam dan Lingkungan. Gramedia. Jakarta.

Ghozali, I. 2009. Aplikasi Analisis Multivariate dengan Program SPSS. Edisi Ke 4. Universitas Diponegoro. Semarang.

Indah, MS. 2009. Valuasi Ekonomi Manfaat Rekreasi Taman Hutan Raya Ir. H. Djuanda Dengan Menggunakan Pendekatan Travel Cost Method. Skripsi. Departemen Ekonomi Sumber Daya Dan Lingkungan. Fakultas Ekonomi dan Manajemen. Institut Pertanian Bogor, Bogor.

Jala, Nandagiri. 2015. Evaluation of Economic Value of Pilikula Lake using Travel Cost and Contingent Valuation Methods. Journal of Water Resources, Coastal And Ocean Engineering. Vol. 4, p.1315-1321.

Masmaulidia, Diana, dkk. 2017. Penentuan Nilai Ekonomi Keberadaan Dan Nilai Penggunaan Langsung Untuk Pembuatan Peta Zona Nilai Ekonomi Kawasan dan Peta Utilitas Menggunakan Sig (Studi Kasus : Kawasan Kebun Raya Bogor, Kota Bogor. Jurnal Geodesi Undip. Volume 6, No. 4.

Prenada, A. 2016. Penilaian Jasa Wisata Kebun Binatang Bumi Kedaton Resort Di Bandar Lampung : Penggunaan Metode Biaya Perjalanan. Skripsi. Fakultas Pertanian. Universitas Lampung, Bandar Lampung.

Pramudhito, A. 2010. Aplikasi Biaya Perjalanan (Travel Cost) Pada Wisata Alam Studi Kasus Air Terjun Jumog kabupaten Karanganyar. Skripsi. Fakultas Ekonomi Universitas Sebelas Maret. Surakarta.

Setiawan, Endang. 2013. Valuasi Ekonomi Jasa Lingkungan Wisata Alam Taman Nasional Gunung Gede Pangrango Dengan Menggunakan Metode Travel Cost Method. Journal of Sustainable Financing for Biodiversity Conservation Through Payment for Environmental Services.

Suparmoko et al. 2014. Valuasi Ekonomi Sumberdaya Alam Dan Lingkungan. Edisi 1. Yogyakarta : Fakultas Ekonomika dan Bisnis UGM. 